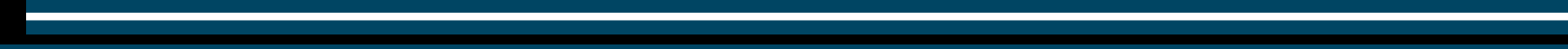




\section{€l Paisaje de la Ruta Libertadora en Boyacá como Patrimonio cultural}

\section{The liberty route's landscape in Boyacá as a cultural heritage}

\author{
Palabras clave: \\ Patrimonio, paisaje, cultura, \\ historia, gestión. \\ Key words: \\ Heritage, landscape, culture, \\ history, management.
}

Recibido: 19 de abr. 2012 Aceptado: 14 de sep. 2012

\footnotetext{
* Profesora Titular y Decana de la Facultad de Arquitectura y Bellas Artes de la Universidad de Boyacá. Directora del grupo de investigación Patrimonio y Memoria -PAME-. Arquitecta de la Universidad Piloto de Colombia. Magíster en Historia de la Universidad Pedagógica y Tecnológica de Colombia
}

${ }^{1}$ Este artículo hace parte de la investigación Macro propuesta por el grupo de investigación en Patrimonio y Memoria - PAME - adscrito a la facultad de Arquitectura y Bellas Artes de la Universidad de Boyacá, el cual desarrolla como proyecto la Resignificación Patrimonial de la Ruta Libertadora en Boyacá. Visión 2019, cuyo objetivo es reivindicar el territorio a partir del patrimonio cultural. mlmesa@uniboyaca.edu.co

\section{Resumen:}

En el presente artículo se revisa el tema del valor del paisaje como patrimonio cultural en el territorio comprendido por la Ruta Libertadora en Boyacá. La presentación comprende la aproximación a experiencias que han visto en el paisaje un patrimonio cultural mundial o local. Al considerar distintos lugares se tienen en cuenta los procesos de recuperación, salvaguardia o protección desarrollados mediante mecanismos o lineamientos potenciados por organismos como la Unesco y los Ministerios o entidades de cada país. En el caso colombiano, desde el Ministerio de Cultura se han definido políticas apoyadas en la ley que paulatinamente han avanzado en el cumplimiento de metas con el respaldo de los entes departamentales públicos y privados.

La revisión de experiencias confiere un panorama sobre la gestión llevada a cabo en el propósito de lograr el reconocimiento del paisaje en su dimensión de patrimonio cultural de las naciones. Tal valoración resulta pertinente en el proyecto que busca resignificar patrimonialmente la Ruta Libertadora, pues permitiría establecer una metodología facilitadora en la construcción de un modelo cuya aplicación conlleve a encontrar sentidos actuales a este contexto histórico, con base en un enfoque definido por el arraigo y la pertinencia.

\section{Abstract}

This paper examines the value of landscape as cultural heritage in Boyacá's Liberty Route (Ruta Libertadora) territory. There are presented approaches to experiences which have found in landscape a cultural heritage for the whole world or for a specific region. There are taking in account recovery, safe, or protection processes, which have been undertaken in different places by organizations such as Unesco, ministries or each country entities. In Colombia, Ministry of Culture has defined policies supported in law which have advanced in fulfillment of goals, thanks also to the support of public and private regional authorities.

By reviewing experiences is given an overview about the efforts carried out in order to attain the landscape's recognition as cultural heritage of nations. This assessment is pertinent for the project of stating a new hereditary meaning to the Liberty Route; since it could define an appropriated methodology for building a framework whose practice allow finding current explanations -based on identity and pertinence- to this historical context. 
El paisaje cultural, al ser trascendido en su condición básica de espacio geográfico delimitado y ser comprendido como una interacción social de redes visibles e invisibles, se ha convertido en un tema relevante de estudio, especialmente cuando se abordan los problemas del territorio y de su uso por parte del hombre.

En este orden de ideas, desde el grupo de investigación en Patrimonio y Memoria -Pame ${ }^{2}$ - se han planteado estrategias para la resignificación de la Ruta Libertadora en Boyacá. Como punto de partida se ha contemplado la revisión de varios horizontes

\section{INTRODUCCIÓN}

que confieren importancia actual a este territorio, conformado por más de 20

municipios enmarcados dentro del paisaje boyacense, escenarios usualmente reconocidos en Colombia por su belleza y valor histórico.

A partir de esta premisa y con el propósito de conferir un nuevo valor al paisaje cultural de la Ruta, Pame ha revisado experiencias similares que bien pueden coadyuvar en la construcción de una metodología específica para abordar la resignificación planteada. Tal recorrido se presenta en este artículo, de tal suerte que, mediante el reconocimiento de los casos, la normatividad y los conceptos, sea posible evidenciar esa indisoluble relación definida entre el medio ambiente y el ser humano, en la cual este último se manifiesta a través de maniobras diversas, participa con mayor o menor intensidad y establece modelos y patrones con su contexto, enfocados a fines diferenciados. 


\section{APROXIMACIÓN AL CONCEPTO DE PAISAJE CULTURAL}

Ante todo, es necesario abordar la noción de cultura. Si bien ha sido definida desde múltiples enfoques y disciplinas, suele comprenderse como la suma de aquellas formas y expresiones que proporcionan una idea perdurable de un grupo humano. Tal concepción general se compagina con la definición formulada por la Unesco en 1982: "conjunto de los rasgos distintivos, espirituales y materiales, intelectuales y afectivos que caracterizan una sociedad o un grupo social. Ella engloba, además de las artes y las letras, los modos de vida, los derechos fundamentales al ser humano" (párr. 5).

La misma Unesco (2005) ha señalado cuatro etapas en la evolución del término, entre las últimas décadas del siglo $\mathrm{XX}$ y los comienzos del XXI:

1) Años 1950 y 1960: se registra una ampliación, desde una visión más ligada a

Inicialmente se efectúa un acercamiento al concepto de paisaje cultural y a sus antecedentes. Se presta especial atención a la perspectiva cultural y a las definiciones promulgadas por instituciones como la Organización de las Naciones Unidas para la Educación la Ciencia y la Cultura (Unesco)

A continuación, se refieren varias experiencias de gestión registradas en contextos nacionales e internacionales, para finalizar con una caracterización de la Ruta Libertadora como eje fundamental de desarrollo en Boyacá, condición que se posibilitaría, precisamente, mediante la gestión y promoción de su paisaje cultural. la producción artística, para abarcar el terreno de la identidad cultural; 2) 1970 y 1980: se toma conciencia de la unión vital entre cultura y desarrollo, vínculo que se acogerá como base de la cooperación internacional; 3) 1980 y 1990: se evidencian las bases culturales en la construcción de las democracias; 4) 1990 y 2000: se orienta hacia la puesta en valor del diálogo de culturas.

Estos postulados han permitido relacionar varios conceptos con fines propositivos, integrales y visión de futuro. En esta articulación, el valor de la naturaleza y los paisajes -con mayor o menor intervención humana- ha adquirido preponderancia.

Por su parte, el paisaje es un concepto moderno cuyos orígenes se remontan a la pintura del Renacimiento Italiano. Posteriormente, con la acción de la Geografía consolida una identidad propia en el siglo XIX. Este hecho es comentado por Navarro (2004): "Ello ocurre en el marco de lo que fue el estudio de una Geografía antropocéntrica que consistía fundamentalmente en el estudio de la parte visible del territorio" (p. 5). En este contexto aparece la palabra rusa Landschaftovédenie, que significa ciencia del paisaje, a propósito del enfoque cientificista otorgado por los geógrafos europeos a los trabajos relacionados con cuestiones paisajísticas. 
La evolución del término desde su conexión con la Geografía es comentada por Frolova (2001), quien concluye: "Los problemas epistemológicos de esta nueva concepción de paisaje permanecen todavía lejos de ser resueltos durante la primera mitad del siglo $X X$ (...) La 'naturalización' y la 'objetivización' del paisaje corresponden al espíritu general de la época" (p. 3). Durante aquel siglo se involucra al hombre en esa nueva visión, de tal forma que más allá del examen centrado en lo netamente físico, los espacios son entendidos como una totalidad.

\footnotetext{
Al abordar el paisaje, Lynch (2000) destaca la importancia de las percepciones elaboradas por los individuos acerca de lo que ven, gracias a las cuales obtienen "sensaciones visuales de color, forma o movimiento" (p. 13).
}

Es así como los escenarios físicos desempeñan una función vital, pues en la interacción de las personas con el entorno se producen experiencias comunicativas que, de acuerdo con su grado de legibilidad, se traducen en impresiones diversas. Esta valoración se asocia con lo enunciado por Ruiz, Velarde y Picher (2006), quienes explican el paisaje como un medio con poder evocativo donde se articulan sonidos, olores, gustos, sensaciones visuales y táctiles.

Así, el heterogéneo y cambiante espectro de las relaciones socioespaciales ofrece numerosas posibilidades de análisis. En el caso de los geógrafos, la mayoría de estudios han centrado su atención en patrones de asentamientos, parcelaciones, arquitectura, y más recientemente, en áreas relacionadas con la recreación.

La discusión referente al paisaje como un elemento cultural surgió hace alrededor de 50 años y ha alcanzado visibilidad con el reconocimiento de varios espacios paisajísticos como patrimonio por parte de la Unesco (1982). El paisaje cultural refleja los esfuerzos de las comunidades por obtener alimentos, abrigo, energía y movilidad. Según lo sostiene Nogué (2007), la interacción hombre-entorno también puede considerarse un concepto social, resultante de las múltiples miradas que alternativamente se oponen y complementan cuando se experimenta el territorio.

La amplitud del concepto lo ha convertido en tema de trabajo constante entre distintas disciplinas, especialmente aquellas relacionadas con la transformación de los territorios y la interacción entre éstos y las sociedades que los ocupan. A su vez, varias de esas áreas, basadas en sus intereses, han contribuido a consolidar la definición del concepto. Entre ellas se encuentran la Arquitectura, el Urbanismo, la Sociología, la Antropología, la Ecología, la Sicología y la Arqueología. Desde esta última, Molano (1996) aporta una apreciación relacionada con la comprensión de 
los espacios geográficos, al resaltar que cuantos "hoy vemos, usamos, estudiamos y continuamos transformando bajo condiciones más inestables 0 equilibrios más precarios; tienen una génesis, expresan una herencia ecológica y ambiental, contienen testimonios de procesos sociohistóricos y simbolizan los elementos de las culturas que los recrean" (p. 2). De tal modo, se introduce una categoría cuyo fundamento radica en la historia espacio temporal del territorio analizado y de quienes lo habitan.

Las reglas del método, cuya revisión ha sido abarcada desde la Sociología, constituyen un aporte al manejo del paisaje cultural. Estos planteamientos proponen la observación de hechos sociales verificables que, de acuerdo con Durkheim (1956), pueden ser "modos de actuar, pensar y sentir externos al individuo, y que poseen un poder de coerción en virtud del cual se imponen a él." (p. 5). Desde esta óptica, el paisaje es concebido como parte integral de la cultura, un componente de las sociedades, y a su vez, regulador de la existencia de éstas.
Llama la atención que este paisaje sea aún algo novedoso en el Urbanismo. Ahora bien, si se considera el amplio campo de trabajo actual de dicha ciencia, como es el análisis e interpretación de la sociedad con base en el conocimiento y la proyectación de ciudades y territorios (según lo especifica Buraglia, 2003), se encuentra una convergencia con el ya referido nexo entre las comunidades y su entorno. Los desafíos planteados por el crecimiento de las urbes, la apropiación de espacios, la urbanización, el poblamiento y las migraciones, expresan la interrelación y el intercambio permanente entre los paisajes y sus ocupantes. En este sentido tendría cabida lo señalado por Campos (2003) al acotar que la humanidad, paulatinamente, se ha apartado de la "estricta relación materialista con su territorio para asumirlo desde una dimensión quizás espiritual" (p. 45).

La conjunción ente el hábitat y el hombre también ha sido considerada en las caracterizaciones que de los paisajes culturales han efectuado diferentes organismos. En esta dirección, la Unesco (2006) ha visto en estos escenarios una combinación -compuesta por disímiles manifestaciones- del trabajo humano y la naturaleza, registrada en un espacio concreto y cuyos componentes significativos son el sustrato natural, la acción de las personas y la actividad ejercida. Tal concepción ha servido de apoyo al analizar los sitios postulados por los países para ser declarados como paisajes patrimoniales de la humanidad, de acuerdo con las siguientes categorías: 


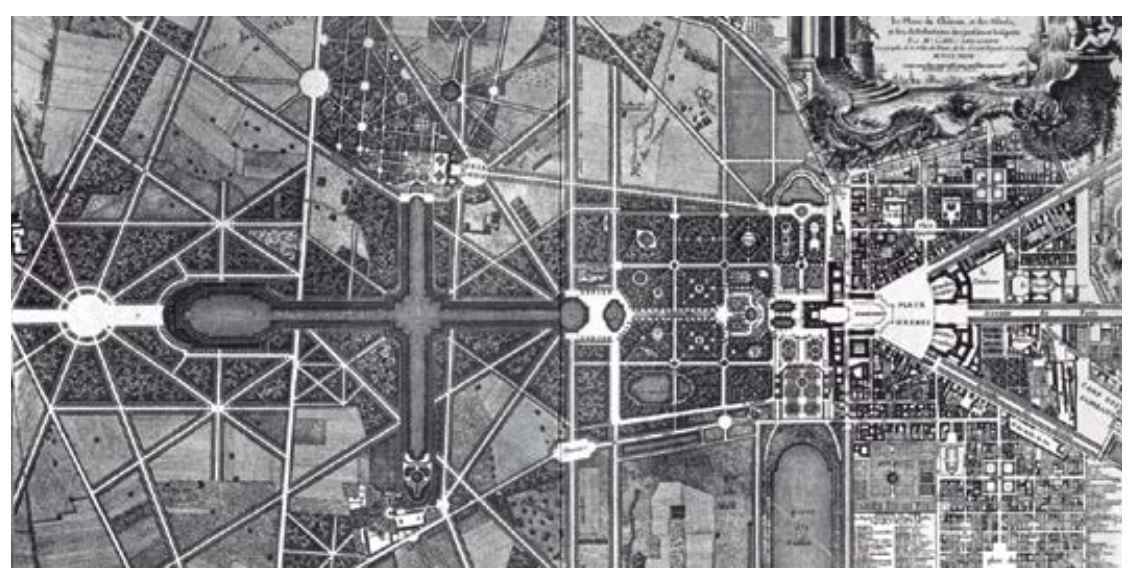

Figura 1. Plano de Versalles en 1746, por Abbé Delagrive, geógrafo de la ciudad de París Fuente: www.histgeographie.com

- Paisajes evolutivos (u orgánicamente diseñados).

Son el resultado de condicionantes sociales, económicas y políticas, entre otras. Tal es el caso de los cultivos de arroz en Indonesia, donde se aprovechan las características geográficas y se privilegia la interacción de los pobladores con el medio en aras de alcanzar el objetivo planteado, como es la producción del cereal en una atmósfera de armonización con el entorno.

- Paisajes claramente definidos.

Diseñados y creados intencionalmente por el hombre, comprenden los jardines y los parques. Evidencian la acción humana sobre el espacio, al cual transforman e intervienen de manera radical. Un ejemplo son los jardines del Palacio de Versalles en Francia.

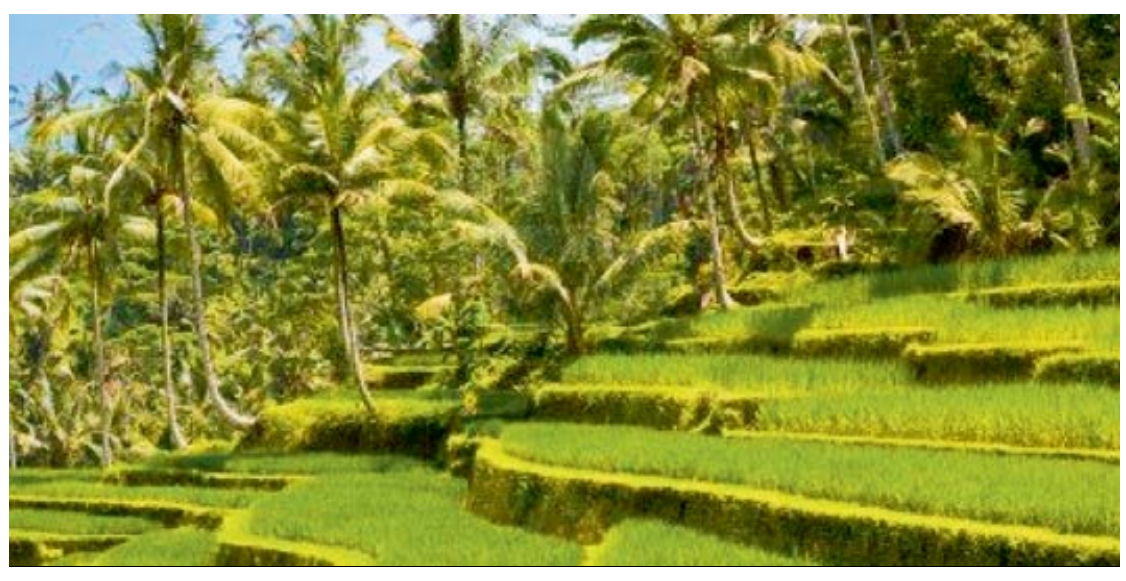

Figura 2. Cultivos de arroz en Indonesia Fuente: http://es.123rf.com/photo_6855320_tipo-en-terrazas-de-arroz-bali-indonesia.html 


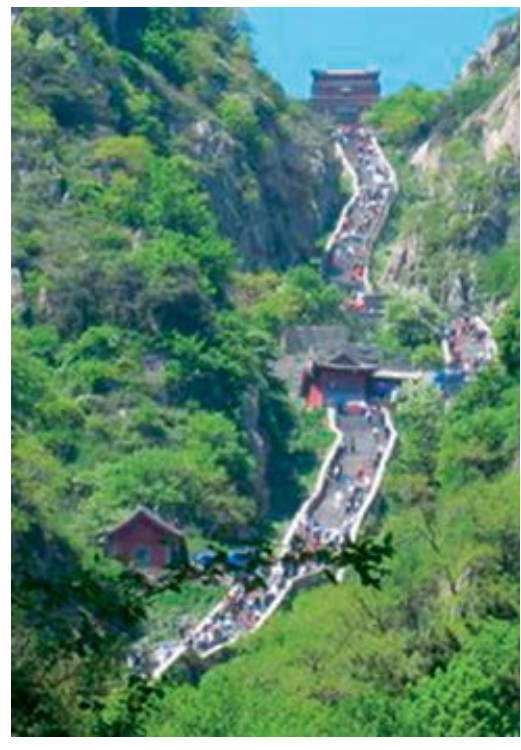

Figura 3. Montes sagrados de Taishan Fuente: http://www.unesco.org/es/nhk-world-heritage

${ }^{3}$ Ley 1185 de 2008, que modificó y adicionó la ley 397 de 1997.

\section{- Paisajes asociativos.}

Están asociados a factores religiosos, artísticos o culturales inherentes al medio ambiente. Representante de esta categoría son los Montes Sagrados de Taishan (China).

En el contexto colombiano, primero en la Ley 397 de 1997 y lueso en la reforma que a ésta se efectuó en 2008 por medio de la Ley General de Cultura ${ }^{3}$, el patrimonio cultural fue definido de manera precisa. En tal descripción, entre los elementos constitutivos de dicho acervo se menciona al paisaje cultural, razón que ha llevado a calificar su salvaguarda, recuperación, conservación y sostenibilidad como objetivos principales, pues a través de estos mecanismos es factible afianzar su condición de testimonio de la identidad. Respecto a esta última dimensión, según González (2006) debe ser entendida como una reafirmación de la pertenencia, el arraigo y la permanencia, en estrecha relación con el territorio.

En este punto es oportuno mencionar uno de los primeros acuerdos que fijó medidas y directrices orientadas a ver el paisaje como un conjunto integrado por elementos materiales y culturales. El Convenio Europeo del Paisaje (CEP), auspiciado por el Consejo de Europa, fue firmado en Florencia (Italia) en el año 2000 y entró en vigencia en 2004. Su objetivo fundamental ha sido promover la protección, gestión y ordenación de los escenarios paisajísticos de este continente por medio de un sólido marco que sitúa a dichos espacios en un primer plano entre las políticas relacionadas con patrimonio cultural, medio ambiente y ordenamiento territorial. Además, en una postura novedosa y afín a los propósitos trazados para el estudio de la Ruta Libertadora en Colombia, introduce una dimensión social y confiere especial atención al vínculo establecido entre los individuos y el contexto donde habitan. 
Esa orientación puede verse en el Artículo 1 del Capítulo l, correspondiente a las Disposiciones Generales, cuando los "objetivos de calidad paisajística" son definidos como la formulación, por parte de las autoridades públicas y competentes, de las aspiraciones de las personas en lo concerniente a las características de su entorno. Asimismo, precisa que la "protección de los paisajes" abarca todas las acciones encaminadas a mantener los aspectos significativos o característicos de un lugar, justificados de la configuración natural o de la acción humana.

Para concluir esta aproximación, cabe recalcar que al hablar del territorio siempre está implícito el paisaje. Incluso, podría afirmarse que las dos nociones son casi lo mismo. En tal sentido encuentra pertinencia lo planteado por Galindo y Sabaté (2009), quienes proponen como eje articulador de los planes de ordenamiento territorial la protección del paisaje, toda vez que éste constituye "la expresión de la memoria, de la identidad de la región" (p. 23). Ciertamente, en el fondo de ese estrecho vínculo subyace la necesidad de proteger el valor de los elementos patrimoniales presentes en las construcciones físicas y culturales de los espacios.

\section{ESTRATEGIAS DE GESTIÓN}

La valoración del paisaje depende en gran medida de los procesos que se realicen para entender su significado, intervenirlo y adecuarlo a exigencias específicas. Al respecto, resulta procedente pensar en lo que realmente es, desde los sistemas macro compuestos por relaciones ecológicas, espaciales y culturales, hasta los mundos de organismos invisibles al ojo humano y solo observables mediante el microscopio. Luego de esta comprensión, como lo proponen Ruiz, Velarde y Picher (2006), es posible definir responsabilidades sobre su protección y gestión.

Si bien toda valoración está supeditada a un enfoque, los atributos que se presentan a continuación, definidos por Ruiz, Velarde y Picher (2006), pueden constituir un modelo a seguir en este clase de ejercicios, ya que revisan lo general y lo particular, lo material y lo inmaterial. Así, otorgan un amplio espectro de posibilidades para efectuar el proceso valorativo:

- Atributos físicos, lo visible y medible (forma del terreno);

- Estéticos y artísticos, abstracción de lo físico (textura, color);

- Psicológicos o no visibles (la expresión). 
En toda valoración, como quiera que se trata de un componente en la gestión del paisaje cultural, es necesario considerar los criterios concebidos y afianzados en las reuniones temáticas de expertos, convocadas por la Unesco. Un primer punto a tener en cuenta es la asociación del concepto de cultura con la mentalidad europea. $\mathrm{Al}$ menos, esto fue así en las primeras categorizaciones que de los espacios paisajísticos hicieron organismos internacionales. Tal trasfondo se aprecia en los listados de los lugares inscritos para ser aceptados como patrimonio cultural, en su mayoría ubicados en Europa y Asia.

Otro punto fundamental al gestionar el paisaje es tener plena claridad sobre la condición de integralidad que le es inherente, y con esta perspectiva, asumir al hombre como parte de ese conjunto. $\mathrm{Al}$ respecto, el mismo CEP (Consejo de Europa, 2000) ve en la gestión la suma de acciones dirigidas, desde una perspectiva de desarrollo sostenible, cuya finalidad es garantizar el mantenimiento de un espacio, guiar y armonizar las transformaciones inducidas por las dinámicas humanas sociales, económicas y medioambientales. Difícilmente puede haber paisaje sin personas y personas sin paisaje. Este nexo otorga valor a la cultura de un territorio, e incluso, llega a determinar los tipos sociales que allí interactúan.

Precisamente, las actuales políticas mundiales apuntan a que las naciones creen, aprueben e implementen las normativas y los incentivos para la preservación y el manejo del paisaje cultural con un enfoque sistémico y no a partir de una atención centrada solo en ciertos hitos. La consecución de este propósito implica una gestión atenta a la formulación de planes de intervención cuyo rumbo contemple la cooperación entre regiones o comunidades, al tiempo que apunte a la satisfacción íntegra de las personas (habitantes o visitantes) por medio de acciones heterogéneas, desde el ocio hasta proyectos productivos sostenibles.

Para Ferro (2009) los paisajes son fuentes de conocimiento y huellas memorables que recuperan la memoria colectiva y brindan la posibilidad de ver en el presente una historia en permanente elaboración. Ciertamente, en ellos se reúnen pequeños relatos, otros locales y aquellos referidos al desarrollo de un país. De ahí la importancia de diseñar y aplicar, dentro de ese panorama de planeación y proyectación, instrumentos y guías especializadas que conlleven a valorar la carga discursiva, simbólica e histórica de los lugares.

Es preciso enfatizar que los elementos del paisaje, entre ellos los de índole patrimonial, no pueden ser analizados o entendidos aisladamente, sin abarcar la totalidad del contexto donde se encuentran inmersos. Al respecto, Querol (2010) indica: "el valor de muchos bienes del patrimonio cultural no se considera circunscrito a su propia materialidad, sino también a la red de conexiones territoriales que les caracteriza y da sentido" (p. 168). Examinar ese todo de manera sistémica, en consonancia con principios de distinto orden (políticos, históricos, medioambientales) es uno de los mayores desafíos de la gestión. 


\section{EXPERIENCIAS SIGNIFICATIVAS DE GESTIÓN}

Son varias las experiencias, registradas en todos los continentes, que dan cuenta de procesos de gestión de paisajes culturales. Un común denominador es la prevalencia de objetivos orientados a impulsar la protección de los espacios en cuestión y ver en ellos escenarios donde se evidencia la interacción entre agentes.

Entre múltiples casos europeos, sobresale la planeación territorial en el Camino de Santiago de Compostela, durante su paso por una zona específica de España. Ponderada como la vía principal de Europa, fue inscrita en 1993 y proclamada en 1997. Presenta alrededor de 1800 edificios o edificaciones religiosas y ha sido reconocida desde la Edad Media por su intercambio comercial y cultural. En especial, se considera uno de los más fuertes testimonios de la fe cristiana.
Según lo formulan Masía y Andrés (2011) la propuesta apunta a establecer una metodología para potenciar el desarrollo urbano, económico y social de las regiones de influencia de esta ruta, entendida como un eje articulador. Sobre el particular, de acuerdo con Masía y Andrés, los objetivos del Plan Regional del Camino están asociados con su protección, recuperación y revitalización a su paso por Castilla y León, "definiendo un corredor estratégico, canalizador de actuaciones que contribuyan al desarrollo racional y sostenible de las poblaciones atravesadas" (p. 4). Así, se abarca el medio ambiente, la preservación de espacios, el patrimonio cultural y el planeamiento urbanístico, en concordancia con las necesidades planteadas por el propio sendero. Además, la metodología enunciada contempla que el turista y el peregrino, tengan amplias opciones de conocer nuevas culturas y costumbres.

También en España, el paisaje minero representa otro referente sobresaliente. La investigación realizada por lbañez (2009) da cuenta de cómo se han asumido y compaginado allí los valores patrimoniales con los industriales: musealización de la herencia técnica para evidenciar la historia local; generación de un turismo especializado e introducción de intervenciones a partir de prácticas artísticas contemporáneas. Esto último se traduce en una forma novedosa de recuperar los valores sociales inmersos en el territorio, de ahí su valor para el tema del paisaje.

En Latinoamérica se encuentra el Camino del Inca, conocido también como el Camino Principal Andino. Según la descripción de la Unesco (2004), se trata de la columna vertebral del poder político y económico de la cultura Inca, constituido por una red de más de $23000 \mathrm{~km}$ de largo que conectaba varios centros de producción, administrativos y ceremoniales, construidos durante más de 2000 años cuyos orígenes se remontan a tiempos previos a la consolidación del imperio prehispánico. Su gestión fue iniciada por Perú en 2001 y en los años siguientes se sumaron al proyecto Argentina, Chile y Bolivia, países que diseñaron un documento referente a las rutas andinas precolombinas. 


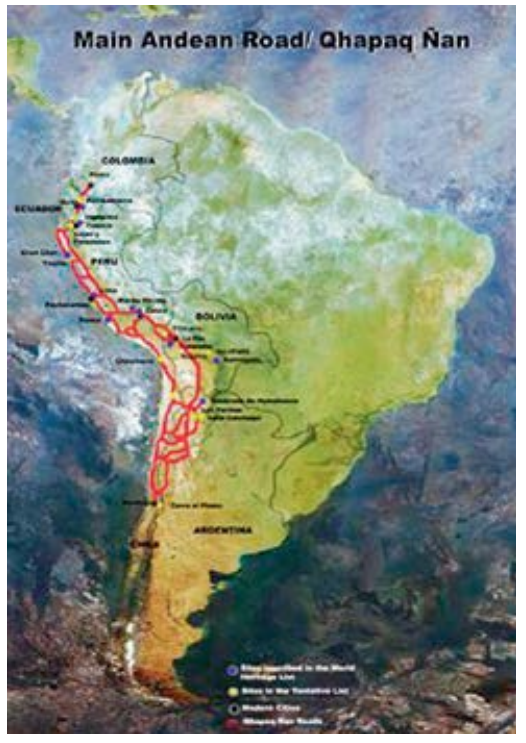

Figura 4. Qhapaq Ñan - Camino Principal Andino Fuente: http://whc. unesco.org/es/actividades/65/

La historia de este camino remite al progreso y al desarrollo logrado por los Incas. Los senderos se adaptaron a la difícil topografía para propiciar intercambios comerciales, políticos y religiosos, de tal forma que operaron como un telón de fondo en la integración de pueblos y paisajes.

Como destaca la Unesco (2004), la civilización Inca diseñó su red en una escala continental, por consiguiente, esta expresión del espíritu de distribución y planificación de la mano de obra, constituyó un instrumento clave en la unificación física y organizacional del imperio.

La vigencia del legado ha sido una de los razones para emprender proyectos de gestión, de los cuales es posible tomar referentes valiosos desde el punto de vista metodolósico. A lo largo del trayecto se ha conceptualizado y ejecutado un trabajo participativo que involucra municipios y culturas. Sobresale el acompañamiento del Centro del Patrimonio Mundial, al auspiciar encuentros técnicos encaminados a preservar este bien, inscrito en la lista tentativa de sitios patrimoniales de la Unesco. Asimismo, las acciones conjuntas adquieren relevancia en términos de la integración latinoamericana, pues otorgan notoriedad al valor de la memoria histórica colectiva como factor de progreso para las naciones, al tiempo que reivindican y revitalizan la herencia prehispánica.

En Argentina, la Ruta de la Yerba Mate es un itinerario sustentado en la cultura de la yerba mate, planta empleada en la preparación de una tradicional bebida y de numerosos productos derivados. Si bien el recorrido privilegia un enfoque turístico, durante el tránsito a través de las provincias de Corrientes y Misiones se expone el proceso de elaboración, su evolución en el tiempo y los rasgos, mitos y costumbres de los habitantes.

La gestión en torno a esta Ruta ha posibilitado la realización de actividades diversas, pues además de las directamente vinculadas con el proceso productivo, se han incluido otras inherentes a la naturaleza, la historia, la gastronomía y los entretenimientos de la región. Como se cuenta en $L_{a}$ Ruta de la Yerba Mate (2012) los procesos de administración y divulgación de este patrimonio se han consolidado gracias a la celebración de alianzas estratégicas con socios como los propios yerbateros, las agroindustrias, los hoteles, restaurantes y centros de arte. 
Colombia también ha tenido presencia en materia de gestión del paisaje. En este sentido, uno de los momentos más significativos ha sido la declaración emitida en la sesión 35 del Comité de Patrimonio Mundial de la Unesco (celebrada en junio de 2011 en París), en la cual se catalogó al paisaje cafetero como patrimonio cultural de la humanidad. En la obtención de este logro se contó con la participación de la red de universidades del eje cafetero (denominadas Red Alma Máter), las sobernaciones de Caldas, Quindío, Risaralda y el Valle de Cauca.

La declaratoria habla de un paisaje productivo en torno a la tradición del cultivo del café. Así lo afirma Nuria Sanz, jefa de la sección América Latina y el Caribe del Centro del Patrimonio Mundial de la Unesco, al resaltar que la relevancia histórica y la raigambre del proceso sociocultural del café no encuentran comparación en el resto de los continentes. En este reconocimiento no solo se valoró la escenografía de los lugares, sino también el carácter empresarial que ha logrado posicionar al grano como uno de los de mejor calidad en el mundo.

Luego de este reconocimiento se emprendieron acciones de gestión, entre ellas, la conformación y proyección mundial de la Ruta del Café. En este paisaje se han trabajado conceptos como el de territorialidad, que desde la perspectiva de Echeverría (2000), corresponde a un ejercicio realizado con la mediación de varios puntos de vista, cuyo impacto se expresa en la demarcación, caracterización y consolidación de un territorio. Tales procedimientos generan un sentido de pertenencia por parte de quienes han intervenido y apropiado un lugar, a tal punto que lo arraigan en la memoria y los imaginarios colectivos.

\section{Ese sentido del territorio se descubre en las expresiones visibles e invisibles, tanto de marcas y registros personales y colectivos, que conjugan identidades y pertenencias, memorias, percepciones e imaginarios de los sujetos que lo habitan, como de registros de la historia, la coyuntura y las tendencias internas y externas, de las fuerzas económicas, sociales, culturales, históricas, tecnológicas. Desde ese sentido propio se establecen intercambios internos y externos que bien pueden confirmar y dar solidez a la naturaleza del mismo territorio, o pueden "hibridarlo" o desestabilizarlo hasta llegar a hacerlo desaparecer. (Echeverría, 2000, p. 7).}

Desde la formulación inicial del proyecto la meta fue buscar sostenibilidad, desarrollo económico y social, sin olvidar la identidad regional como motor de la caracterización. En este orden de ideas, la gestión efectuada para la obtención de la declaratoria suscitó numerosas preguntas en torno a si el paisaje cafetero es solo café. Si bien dicha reflexión ha motivado debates, es innegable que la reconocida tradición en el cultivo, manejo y comercio del grano, ha sido determinante en la configuración simbólica y física del territorio. Finalmente, en la propuesta se incluyeron 47 municipios, 411 veredas y 24.000 fincas, con una población estimada de 80.000 personas cuya vida gira alrededor de esta labor. 


\section{EL PAISAJE EN LA RUTA LIBERTADORA}

Para revisar esta Ruta, cuya relevancia trasciende el contexto de Boyacá y se sitúa en la idea misma de la nacionalidad colombiana, es procedente identificar primero otro concepto, como es el de Itinerario Cultural. De acuerdo con lo precisado por la Unesco (2006) se trata de una articulación territorial basada en el diálogo, la movilidad y los intercambios entre varias regiones, que si bien pueden pertenecer a diferentes divisiones político-administrativas, interactúan y comparten una pluralidad en múltiples dimensiones, desde lo religioso hasta la comercial.

\section{Un ejemplo de esos itinerarios,}

declarado por la Unesco como el primero de su tipo en Europa y también elevado a la condición de patrimonio de la humanidad, es precisamente el Camino de Santiago de Compostela.
El itinerario suele ser cubierto por miles de peregrinos, procedentes no solo de Europa sino de varios países de la cristiandad, quienes realizan el recorrido por España, Francia y Portugal con el fin principal de llegar hasta la tumba que, según la tradición católica, pertenece al apóstol Santiago.

Revisada esta noción es posible descubrir su aplicación en la Ruta Libertadora. Por lo general, el trayecto ha sido abordado desde una perspectiva histórica, en razón de los sucesos ocurridos en 1819 durante la campaña independentista de la actual Colombia. Ahora bien, en la investigación formulada por el grupo Pame se apunta como eje central a potenciar su resignificación. Se ha concebido entonces un plan estratégico que involucra distintas aristas para el análisis, tras considerar la Ruta más allá de la elemental visión de recorrido lineal -transitable en términos de movilidadpara ver en ella una suma de territorios conformados a partir de los fastos memorables, pero cuya evocación rebasa la epopeya y remite a complejas realidades y disímiles sentidos. Entre esos espacios se encuentran los municipios de Socotá, Pisba, Paya, Socha, Tasco, Miraflórez, Busbanzá, Santa Rosa de Viterbo, Tunja, Toca, Gámeza, Tópaga, Belén, Cerinza y Ventaquemada, todos ellos en el departamento de Boyacá. Tras definir el territorio de estudio se definieron las variables, algunas construidas sobre los referentes provistos por las experiencias nacionales e internacionales previamente mencionadas, las cuales han servido para establecer los parámetros a valorar en este paisaje cultural. 


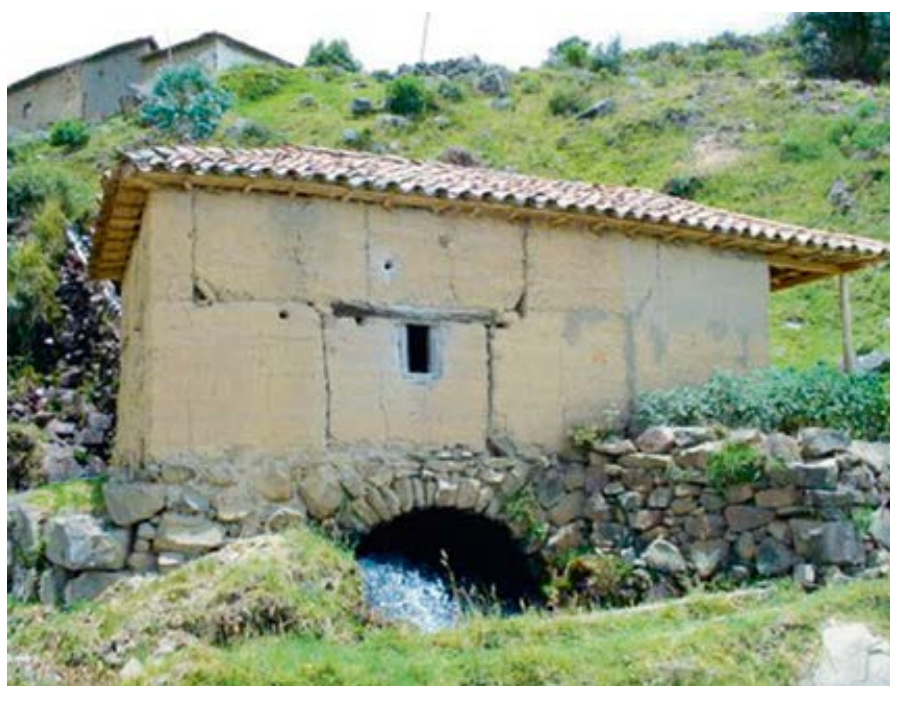

Figura 5. Paisaje Socotense - Boyacá Fuente: Grupo Pame

\begin{abstract}
Al ser el paisaje el eje central, se confiere a la Ruta una visión no contemplada aún en los planes de desarrollo municipales y territoriales. A partir de esta óptica se determinan objetivos de intervención, como son la integralidad del territorio, la preservación de los recursos naturales y patrimoniales, y la implementación de programas destinados a incentivar el desarrollo económico de las regiones integrantes. En este contexto se pone en primer plano la pertinencia de impulsar la cooperación entre los municipios, pues al perseguir una causa común se multiplican las oportunidades para emprender programas de turismo especializado, educación ambiental, conservación del patrimonio material e inmaterial y búsqueda de declaratorias que respalden la visibilidad de cada lugar.

El territorio queda entonces denotado como una articulación donde las imágenes generadas por el paisaje resguardan un legado e invitan a explorar el vínculo entre el hecho histórico, el lugar y su valor vigente. En relación con esta cualidad, Galindo y Sabaté (2009) afirman: "la imagen es fundamental. Y para reforzar la imagen de cada lugar es preciso reconocer su identidad y destacarla" (p. 29).
\end{abstract}


Claro está que la percepción existente sobre el paisaje de la Ruta no es clara, pues éste todavía no ha sido resaltado ni inventariado como un elemento identificable y armonizado con un todo. Por lo tanto, el primer paso a seguir en la propuesta investigativa consiste en diseñar y elaborar los inventarios acordes a las necesidades que el territorio insinúa en términos de sostenibilidad. En dicho cometido debe recurrirse a los modelos propuestos por el Ministerio de Cultura para la valoración de bienes patrimoniales, y cuando se detecten vacíos en la normativa colombiana, la consulta y verificación de las experiencias extranjeras significativas constituye una alternativa.

En segundo lugar, ha de consolidarse un plan de trabajo que clasifique los inventarios por temas específicos, en aras de identificar plenamente los recursos, su estado y posibilidades ante una eventual declaratoria. La ejecución de esta etapa estaría a cargo de un equipo interdisciplinario, encargado de cubrir múltiples frentes. Una vez definido el rumbo se elegiría solo una de las variables afines al tema del paisaje cultural, y de este modo, se emprendería el proceso de acercamiento entre municipios y de reconocimiento y valoración de su potencial.

Así por ejemplo, podría adoptarse una metodología destinada a diseñar un itinerario para recorrer a pie, a caballo o en auto, con el seguimiento de un guión predefinido, distintos pueblos y parajes donde existan bienes patrimoniales cuyo reconocimiento no solo evoque la memoria sino que remita a las complejidades latentes en el lugar y conlleve a pensar en su relevancia y significados, atinentes a realidades sociales y culturales, más allá de lo estrictamente histórico.

\section{CONCLUSIONES}

Entender el territorio con una nueva perspectiva permite enfrentar los retos de un mundo que, a pesar de sus incesantes transformaciones, busca preservar valores elementales con base en entidades como el paisaje cultural, una realidad implícita en el quehacer del ser humano y decisiva para la conformación de su hábitat.

Los grupos humanos residentes en los paisajes culturales interiorizan modos de vida que, en gran medida, son determinados por los valores del territorio. A su vez, los continuos cambios de estas sociedades motivan procesos de resignificación y adopción de nuevos usos para el entorno y sus elementos constituyentes.

La gestión del paisaje está directamente ligada a la del territorio, el cual se entiende como un todo donde interactúan de manera directa o indirecta el hombre, sus construcciones y la naturaleza. Al examinar varias experiencias de gestión se descubren prácticas con grados diferenciados de éxito. No obstante, tales casos esbozan un 
horizonte del que es posible tomar elementos destinados a la formulación de normativas o al diseño de metodologías investigativas replicables.

En este orden de ideas, valorar en su justa dimensión al paisaje de la Ruta Libertadora -en especial en Boyacá- ayudará a comprender un territorio donde se conjugan obras arquitectónicas, áreas arqueológicas, ciudades, pueblos, monumentos y ecosistemas. Simultáneamente, todas estas construcciones materiales están conectadas a tradiciones, oficios ancestrales, relatos costumbristas e imaginarios. En consecuencia, este gran acervo tangible e intangible puede reunir la fuerza simbólica, patrimonial y discursiva que lleve a impulsar una iniciativa -con carácter de proyecto nacional- destinada a incluir el camino en la lista de los espacios paisajísticos patrimoniales de la Unesco.

El paisaje de la Ruta es reconocido en el país por su belleza. Si bien así lo expresan distintos actores, es importante otorgarle su valor real para que sea incorporado en los planes de desarrollo y haga parte integral del histórico territorio. 
REFERENCIAS Buraglia, P. (2003). Apuntes para la definición del urbanismo como disciplina en BIBLIOGRÁFICAS Colombia. Urbanismos, 1, (1), 94-107.

Campos, O. (2003). Del paisaje a la ciudad. Bitácora urbano territorial, 1, (7), 44- 52.

Consejo de Europa. (2000). Convenio Europeo del Paisaje. Recuperado el 12 de febrero de 2012, de http://www.mcu.es/patrimonio/docs/Convenio_europeo_paisaje.pdf

Durkheim, E. (1956). Les regles de la methode sociologique. París, Francia: Presses Universitarires de France.

Echeverría, M. C. (2000). Descentrar la mirada: avisorando la ciudad como territorialidad. En Red de estudios de espacio y territorio (Ed.). Espacio y territorios: razón, pasión e imaginarios (pp. 217-249). Bogotá, Colombia: Universidad Nacional. 
Ferro, G. (2009). Guía de observación etnográfica y valoración cultural a un barrio. Apuntes, 23, (2), 182-193.

Frolova, M. (2001). Los orígenes de la ciencia del paisaje en la geografía rusa. Revista electrónica de Geografía y Ciencias Sociales, V, (102).

Galindo, J. \& Sabaté, J. (2009). El valor estructurante del patrimonio en la transformación del territorio. Apuntes, 22, (1), 20-33.

Gonzalez I. (2006). Conservación de bienes culturales: teoría, historia, principios y normas. Madrid, España: Ediciones Cátedra.

REFERENCIAS BIBLIOGRÁFICAS
Ibañez, M. P. (2009). El paisaje minero en España como elemento de desarrollo territorial. Apuntes, 22, (1), 6-19.

La Ruta de la Yerba Mate. (2012). Recuperado el 4 de marzo de 2012, de http:// www.rutadelayerbamate.org.ar/que-es/ruta-de-la-yerba-mate

Lynch, K. (2000). La imagen de la ciudad. Barcelona, España: Gustavo Gilli.

Masía, L. \& Andrés, C. (2011). Estrategias de planificación territorial: El Plan Regional del Camino en Castilla y León. Urban-e, (1). Recuperado el 13 de agosto de 2012, de http://urban-e.aq.upm.es/articulos/ver/estrategias-deplanificaci-n-territorial-el-plan-regional-del-camino-en-castilla-y-le-n?lang $=3$

Molano, J. (1996). Arqueología del paisaje. Revista Anotaciones sobre planeación, (44), 7-14.

Navarro, G. (2004). Una aproximación al paisaje como patrimonio cultural, identidad y constructo mental de una sociedad. Diseño urbano y Paisaje, 1, (1), 1-15. 
Nogué, J. (2007). La construcción social del paisaje. Madrid, España: Biblioteca Nueva.

Querol, M. (2010). Manual de Gestión del patrimonio cultural. Madrid, España: Akal.

Ruiz, M. A., Velarde, M. D. \& Picher, A. C. (2006). Arquitectura del paisaje. Madrid, España: Servicio de Publicaciones de la Universidad Rey Juan Carlos.

Organización de las Naciones Unidas para la Educación la Ciencia y la Cultura (Unesco). (1982). Declaración de México sobre las políticas culturales. Recuperado el 22 de junio de 2012, de http://portal.unesco.org/pv_obj_cache/ pv_obj_id_F6738ABFE74967624B9752C079285FA381780000/ filename/mexico_sp.pdf

Organización de las Naciones Unidas para la Educación la Ciencia y la Cultura (Unesco). (2004). Tejiendo los lazos de un legado. Qhapaq Ñan Camino Principal Andino. Lima, Perú: Unesco.

Organización de las Naciones Unidas para la Educación la Ciencia y la Cultura (Unesco). (2005). 10 clés pour la Convention sur la protection et la promotion de la diversité des expressions culturelles. Recuperado el 6 de abril de 2012, de http://www.unesco.org/pv_obj_cache/pv_obj_id_B864F1B82E9CBF8C05007D671717EE89792A1C00/filename/10_keys_ fr.pdf

Organización de las Naciones Unidas para la Educación la Ciencia y la Cultura (Unesco). (2006). Los paisajes culturales y la convención del patrimonio mundial cultural y natural: Resultados de reuniones temáticas previas. Recuperado el 2 de diciembre de 2011, de www.condesan.org/unesco/Cap\%20 06\%20metchild\%20rossler.pdf. 